\title{
PENERAPAN METODE WATERFALL PADA SISTEM INFORMASI INVENTORI PT. PANGAN SEHAT SEJAHTERA
}

\author{
Muhamad Tabrani ${ }^{1}$, Eni Pudjiarti ${ }^{2}$ \\ ${ }^{1}$ Tehnik Informatika, STMIK Nusa Mandiri Jakarta \\ Email: muhammad.mtb@bsi.ac.id \\ ${ }^{2}$ Tehnik Informatika, STMIK Nusa Mandiri Jakarta \\ Email: enipudjiarti@nusamandiri.ac.id
}

\begin{abstract}
The goods inventory data processing in PT. Pangan Sehat Sejahtera is still using an application program that has not been fully integrated, meaning that in terms of recording and processing can only be accessed by one ministry that warehouse admin. As a distributor company with multi branches, the reports from branch office to main office have been converted in a such from the inventory application into Microsoft Office Excel form. The reports in excel form should be sent to main office's by email everyday. This system makes the main office can't get the updated inventory data as soon as possible. PT. Pangan Sehat Sejahtera has been using the Internet. The utilization of Information Technology can be maximized by building a web-based goods inventory system applications that can be accessed by the main office and the branch offices. The application was built using the Macromedia Dreamweaver, PHP programming language, and database MySQL. This application can be used by PT. Pangan Sehat Sejahtera especially the warehouse clerk to inventory the products in the warehouse. This inventory includes recording, processing, storage, and reporting the inventory data warehouse. With web-based, main office can see the reports from branch office and know the inventory data of each branch office quickly, precisely, and accurately.
\end{abstract}

Keywords: Sales Information System, Data Processing, Inventory.

\section{ABSTRAK}

Pengolahan data inventori barang di PT. Pangan Sehat Sejahtera masih menggunakan suatu aplikasi program yang belum terintegrasi secara penuh, artinya dari segi pencatatan dan pengolahannya hanya bisa diakses oleh satu departemen saja yaitu admin gudang. Sebagai perusahaan distributor dengan multi cabang, pelaporan dari kantor cabang ke kantor pusat dilakukan dengan cara mengkonversi data inventori dari aplikasi tersebut ke dalam Microsoft Office Excel. Setiap hari laporan dalam format Excel tersebut harus dikirim ke pihak kantor pusat via email. Sistem tersebut menjadikan pihak kantor pusat tidak dapat mengetahui data inventori masing-masing kantor cabang dengan cepat. PT. Pangan Sehat Sejahtera telah terhubung jaringan Internet. Pemanfaatan Teknologi Informasi dapat dimaksimalkan dengan membangun aplikasi sistem inventori barang berbasis web yang dapat diakses oleh pihak kantor pusat dan kantor cabang. Aplikasi dibangun dengan menggunakan Macromedia Dreamweaver, bahasa pemrograman PHP, dan database MySQL. Aplikasi ini dapat digunakan pihak PT. Pangan Sehat Sejahtera terutama petugas bagian gudang dalam menginventarisasi produk yang ada di gudang. Inventarisasi ini meliputi pencatatan, pengolahan, penyimpanan, dan pelaporan data inventori gudang. Dengan berbasis web, pihak kantor pusat dapat melihat pelaporan dari kantor cabang dan dapat mengetahui data inventori masing-masing kantor cabang dengan cepat, tepat, dan akurat.

Kata Kunci: Perancangan Sistem Informasi, Pengolahan Data, Persediaan.

\section{PENDAHULUAN}

Persaingan ekonomi sektor perdagangan semakin pesat, sesuai dengan publikasi Badan Pusat Statistik pada sebuah siaran pers, "Neraca perdagangan Indonesia pada April 2014 mengalami defisit sebesar US\$ 1,96 miliar setelah pada bulan sebelumnya mencatat surplus sebesar US\$ 0,67 miliar" (Peter Jacobs, No.16/43/DKom). Sehingga perlunya pemikiran yang semakin kritis atas pemanfaatan sumber dana dan sumber daya yang ada. Pada dasarnya perusahaan yang didirikan memiliki tujuan, dan tujuan utama perusahaan adalah bagaimana perusahaan dapat menjaga kelangsungan hidupnya dan 
menjaga usahanya agar tetap dapat bertahan dan berkembang maka diperlukan upaya untuk penyempurnaan, meliputi peningkatan, produktifitas, cepat waktu serta mudah dipahami untuk penyampaian tujuan perusahaan dalam segala bentuk persaingan.

Pada sebuah perusahaan atau instansi besar maupun kecil selalu ada inventori barang untuk semua proses transaksi, dengan sistem inventori yang baik berpengaruh sekali bagi perkembangan dan kemajuan suatu perusahan atau instansi terutama yang bergerak dalam bidang perdagangan. Sistem inventori yang kurang baik akan berpengaruh terhadap aspek lain, seperti kurangnya kepercayaan konsumen atau pelanggan terhadap perusahaan.

PT. Pangan Sehat Sejahtera salah satu perusahaan penjualan makanan olahan daging, sistem yang digunakan pada perusahan ini yaitu aplikasi program desktop, yang mana pelaporan antar divisi dilakukan dengan cara menyalin data inventori dari aplikasi program desktop tersebut ke dalam Microsoft Office Excel. Setiap hari laporan dalam format Excel tersebut harus dikirim via email. sehingga memungkinkan terjadinya banyak kesalahan yaitu selisih antara stok barang pembelian yang ada dengan transaksi penjualan serta akan memakan waktu yang lama dalam perhitungan dan penyajian informasi inventori barang kepada pimpinan.

\section{TINJAUAN PUSTAKA}

\subsection{Konsep Dasar Web}

Pembuatan penelitian ini tidak terlepas dari teori-teori yang mendukung dalam mempelajari serta merancang sebuah web. Sebelum penulis merancang sebuah web, penulis mempersiapkan apa saja yang akan digunakan, yaitu Aphace web server, Macromedia Dreamwever CS5, database MySQL, dan browser sebagai media internet. Penulis menggunakan apache sebagai server web. Untuk server aplikasinya penulis menggunakan Macromedia Dreamwever MX2004 yang berfungsi sebagai editor. Sementara untuk server database-nya menggunakan MySQL dan untuk mengaksesnya penulis menggunakan program browser berupa Mozilla Firefox sebagai media internet.

\subsubsection{Internet}

Menurut Wismakarma (2009:1) mengemukakan bahwa "Internet adalah suatu jaringan komputer global terbentuk dari jaringan-jaringan komputer lokal dan regional, memungkinkan komunikasi data antar komputer-komputer yang terhubung ke jaringan tersebut". Internet yang kita kenal saat ini pertama kali dikembangkan pada tahun 1969 dengan nama ARPA Net (US Defense Advanced Research Project Agancy) oleh departetmen Pertahanan Amerika Serikat (Febrian, 2008:27). Kejadian ini berlangsung selama dua bulan setelah Neil Amstrong melangkah ke bulan. ARPA Net dibangun dengan sasaran untuk membuat jaringan komputer terbesar untuk menghindari pemusatan informasi disatu titik yang dipandang rawan untuk dihancurkan apabila terjadi peperangan. Di Indonesia jaringan internet mulai dikembangkan tahun 1983 di Universitas Indonesia berupa UI Net oleh Dr. Joseph F.P Luhukay. Ketika itu dia baru menamatkan program doktor Filosopi Ilmu Komputer di Amerika Serikat (Oetomo, 2007:23).

\subsubsection{Website}

Menurut Ardhana (2012:3) menyimpulkan bahwa: Website atau Situs Web adalah sejumlah halaman web yang memiliki topik saling terkait, terkadang disertai pula dengan berkas-berkas gambar, video, atau berkas lainnya. Situs web merupakan kumpulan dari halaman web yang sudah dipublikasikan di jaringan internet dan memiliki domain/URL (Unifed Resource Locator) yang dapat diakses semua pengguna internet dengan cara mengetikan alamatnya. Ditinjau dari aspek content atau isi, web dapat dibagi menjadi 2 jenis, yaitu web statis dan web dinamis. Selain dari sisi content/isi, web statis dan web dinamis dapat dilihat dari aspek teknologi yang digunakan untuk membuat jenis web tersebut.

\subsection{Bahasa Pemrograman}

\subsubsection{HTML (Hyper Text MarkupLanguage)}

Menurut Ardhana (2012:42) "HTML atau Hyper Text Markup Language merupakan suatu bahasa yang dikenali oleh web browser untuk menampilkan informasi seperti teks, gambar, animasi bahkan video". Untuk dapat membuat website dengan baik maka langkah awal yang harus dilakukan yaitu mengenal kode-kode dasar HTML yang sering digunakan oleh programmer web professional. Kode HTML memiliki aturan dan struktur penulisan tersendiri yang disebut tag HTML. Tag adalah kode yang digunakan untuk memoles (mark-up) teks menjadi file HTML. Setiap tag diapit dengan tanda kurung runcing. Ada tag pembuka dan tag penutup, yang membedakan tag penutup ditandai dengan tanda garis miring (slash) di depan awal tulisannya. Dokumen html merupakan dokumen yang 
disajikan dalam web browser dan biasanya hanya untuk menampilkan informasi maupun interface. Secara umum, dokumen web dibagi menjadi dua bagian, yaitu head dan body, sehingga setiap dokumen html harus mempunyai pola dasar.

\subsubsection{CSS (Cascading Style Sheet)}

Menurut Ardhana (2012:108) CSS atau Cascading Style Sheet merupakan salah satu bahasa pemrograman web untuk mengendalikan beberapa komponen dalam sebuah web sehingga akan lebih terstruktur dan seragam. Sama halnya styles dalam aplikasi pengolahan kata seperti Microsoft Word yang dapat mengatur beberapa style, misalnya heading, subbab, bodytext, footer, images, dan style lainnya untuk dapat digunakan bersama-sama dalam beberapa berkas (files). Pada umumnya CSS dipakai untuk memformat tampilan halaman web yang dibuat dengan bahasa HTML dan XHTML. CSS dapat mengendalikan ukuran gambar, warna bagian tubuh pada teks, warna table, ukuran border, warna border, warna hyperlink, warna mouse-over, spasi antar paragraf, spasi antar teks, margin kiri, kanan, atas, bawah, dan parameter lainnya. CSS adalah bahasa style sheet yang digunakan untuk mengatur tampilan dokumen. Dengan adanya CSS memungkinkan kita untuk menampilkan halaman yang sama dengan format yang berbeda.

\subsubsection{Macromedia Dreamweaver}

Saat ini sudah banyak program aplikasi web editor yang memudahkan orang untuk membuat website dengan mudah dan cepat. Salah satu program aplikasi web editor tersebut adalah Macromedia Dreamweaver 8. Menurut Firdaus (2007:15) mengemukakan bahwa "Macromedia Dreamweaver 8 adalah sebuah perangkat lunak yang dapat digunakan oleh setiap orang untuk belajar bagaimana membuat web dengan mudah. Cara penggunaanya juga sangat sederhana dan gampang dimengerti". Salah satu kekuatan Macromedia Dreamweaver 8 ini adalah kemampuannya mendukung pemrograman script server side seperti Active Server Pages (ASP), ASP.NET, ColdFusion, Java Server Pages (JSP) dan PHP. Selain itu, tentunya mendukung pemrograman client side yang sangat terkenal dan banyak dipakai orang, yakni HTML dan JavaScript. Banyak jenis web editor yang dapat mengelola file PHP, dari shareware sampai dengan yang freeware dan memiliki kemampuan untuk mendukung pemrograman server side dan client side. Server side digunakan untuk memproses data yang berhubungan dengan server seperti pengolahan database, sedangkan client side merupakan bahasa pemrograman tambahan Sebagai editor Dreamweaver mempunyai sifat yang WYSIWYG, artinya apa yang kamu lihat akan kamu peroleh (What You See Is What You Get). Dengan kelebihan ini, seorang programer dapat langsung melihat hasil buatannya tanpa harus dibuka di browser.

\subsubsection{PHP (Personal Home Page)}

Menurut Ardhana (2012:88), "PHP atau Pesonal Home Page merupakan bahasa pemrograman berbasis server-side yang dapat melakukan parsing script php menjadi script web sehingga dari sisi client menghasilkan suatu tampilan yang menarik. PHP merupakan pengembangan dari FI atau Form Interface yang dibuat oleh Rasmus Lerdoff pada tahun 1995". Berbeda dengan HTML, kode PHP tidak diberikan langsung oleh server ketika ada permintaan dari sisi client namun dengan cara pemrosesan dari sisi server. Kode PHP disisipkan pada kode HTML. Perbedaan dari kode (script) HTML dan PHP yaitu setiap kode PHP ditulis selalu diberi tag pembuka yaitu $<$ ? Dan pada akhir kode PHP diberi tag penutup yaitu ?>. PHP sangat berperan besar ketika ingin membuat website keren yang dinamis karena dapat melakukan banyak hal, seperti membaca file, menulis file, menampilkan gambar, animasi atau movie, dan yang paling pokok adalah dapat melakukan koneksi terhadap database.

\subsection{Basis Data}

\subsubsection{MySQL}

Menurut Firdaus (2007:56) "MySQL adalah database yang menghubungkan script php menggunakan perintah query dan escape character yang sama dengan php". Selain itu ia bersifat open source (anda tidak perlu membayar untuk menggunakanya) pada berbaggai platform (kecuali untuk jenis enterprise, yang bersifat komersial). Perangkat lunak mysql sendiri bisa didownload dari http://www.mysql.com. Mysql termasuk jenis RDMS (Relation Database Management System). Itulah sebabnya istilah seperti table, baris, kolom digunakan dalam mysql. Pada mysql sebuah database mengusung satu atau sejumlah table. Tabel terdiri atas sejumlah baris dan setiap baris mengandung satu atau beberapa kolom. Mysql merupakan software yang dikembangkan oleh komunitas umum, dan hak cipta untuk kode sumber dimiliki oleh penulisnya masing- masing. Mysql 
dimiliki dan disponsori oleh sebuah perusahaan komersial swedia yaitu Mysql AB. beberapa kelebihan mysql antara lain;

1. $\quad$ Free (bebas di download)

2. Stabil dan tangguh

3. Fleksibel dengan berbagai pemograman

4. Security yang baik

5. Kemudahan manajemen database

6. Mendukung transaksi

7. Perkembangan software yang cukup cepat.

\subsubsection{Apache2Triad}

Menurut Suprianto (2008:1) "Apache2triad merupakan web server yang digunakan oleh PHP, berfungsi menampilkan hasil proses script PHP ke komputer browser dalam bentuk tag HTML". Web Server merupakan server yang menangani komunikasi data pada internet melalui jalur word wide web (www) atau html (Hypertext Markup Language). Web server merupakan inti dari server- server di internet karena sebagian besar layanan komunikasi berupa HTTP. Pada kenyataanya apabila kita mengakses internet maka layanan yang banyak digunakan adalah web service yaitu layanan berbasis web. Layanan http dapat digunakan karena kita melakukan request pada host yang ada di internet dan host tersebut menanggapinya dengan mengirimkan informasi yang kita butuhkan berupa kode-kode html yang akan dirubah ke bentuk halaman browser oleh web. Apache pertama kali didesain pada system Unix, tetapi pada versi berikutnya apache dapat dijalankan dalam sistem windows.

\subsection{Model Pengembangan Perangkat Lunak}

Pada pengembangan penulis menngunakan metode Air terjun (WaterFall) Menurut Rosa dan M. Shalahuddin (2013:28) Model SDLC air terjun (waterfall) sering juga disebut model sekuensial linier (sequential linier) atau alur hidup klasik (classic life cycle). Model air terjun menyediakan pendekatan alur hidup perangkat lunak secara sekuential atau terurut dimulai dari analisis, desain, pengkodean, pengujian, dan tahap pendukung (support).

1. Analisis Kebutuhan Perangkat Lunak

Proses pengumpulan kebutuhan dilakukan secara intensif untuk menspesifikasikan kebutuhan perangkat lunak agar dapat dipahami perangkat lunak seperti apa yang dibutuhkan oleh user. Spesifikasi kebutuhan perangkat lunak pada tahap ini perlu untuk didokumentasikan.

2. Desain

Desain perangkat lunak adalah proses multi langkah yang fokus pada desain pembuatan program perangkat lunak termasuk struktur data, arsitektur perangkat lunak, representasi antarmuka, dan prosedur pengkodean. Tahap ini mentrannslasi kebutuhan perangkat lunak dari tahap analisis kebutuhan ke representasi desain agar dapat diimplementasikan menjadi program pada tahap selanjutnya. Desain perangkat lunak yang dihasilkan pada tahap ini juga perlu didokumentasikan.

3. Pembuatan Kode Program

Desain harus ditranslasikan kedalam program perangkat lunak. Hasil dari tahap ini adalah program komputer sesuai dengan desain yang telah dibuat pada tahap desain.

4. Pengujian

Pengujian fokus pada perangkat lunak secara dari segi lojik dan fungsional dan memastikan bahwa semua bagian sudah diuji. Hal ini dilakukan untuk meminimalisir kesalahan (error) dan memastika keluaran yang dihasilkan sesuai dengan yang diinginkan.

5. Pendukung atau Pemeliharaan (maintenance)

Tidak menutup kemungkinan sebuah perangkat lunak mengalami perubahan ketika sudah dikirimkan ke user. Perubahan bisa terjadi karena adanya kesalahan yang muncul dan tidak terdeteksi saat pengujian atau perangkat lunak harus beradaptasi dengan lingkungan baru. Tahap pendukung atau pemeliharaan dapat mengulangi proses pengembangan mulai dari analisis spesifikasi untuk perubahan perangkat lunak yang sudah ada, tapi tidak untuk membuat perangkat lunak baru.

\subsection{Tool Program}

Perancangan suatu website tidak terlepas dari penggunaan peralatan pendukung (tools program). Peralatan pendukung dalam perancangan website bisa menambah kemudahan dalam memperoleh prosedur-prosedur yang akan dipakai pada website tersebut. 


\subsubsection{Struktur Navigasi}

Menurut Purnama (2006:12) "Struktur navigasi adalah struktur atau alur dari sebuah program yang biasanya digunakan untuk menghubungkan halaman-halaman web yang berdasarkan elemen-elemen yang digunakan dalam aplikasi web". Struktur navigasi merupakan rancangan hubungan dari beberapa area yang berbeda dan dapat membantu mengorganisasikan seluruh elemen dengan pemberian perintah dan pesan. Peta navigasi memiliki ciri khas yang membedakannya menurut kebutuhan objek, kemudahan pemakaian, keinteraktifannya dan kemudahan yang membuatnya berpengaruh terhadap pembuatan aplikasi multimedia. Beberapa jenis struktur navigasi adalah sebagai berikut:

1. Linear

Suatu jalur (Linear) merupakan struktur yang hanya mempunyai satu rangkaian cerita yang berurutan. Struktur ini menampilkan satu demi satu tampilan layar secara berurutan menurut urutannya. Tampilan yang dapat ditampilkan pada struktur jenis ini adalah satu halaman sebelumnya atau satu halaman sesudahnya tidak dapat dua halaman sebelumnya atau dua halaman sesudahnya. Pada struktur ini tidak diperkenankan adanya percabangan.

2. Non Linear

Struktur tidak berturut (Non Linear) merupakan pengembangan dari struktur Linear. Pada struktur ini diperkenankan membuat percabangan. Percabangan yang dibuat pada struktur Non Linear ini berbeda dengan percabangan pada struktur Hirarki, karena pada percabangan Non Linear ini walaupun terdapat percabangan, tetapi tiap-tiap tampilan mempunyai kedudukan yang sama, tidak ada Master page dan Slave Page.

3. Hirarki

Struktur Hierarchical merupakan suatu struktur yang mengandalkan percabangan untuk menampilkan data berdasarkan kriteria tertentu. Tampilan pada menu pertama akan disebut sebagai Master Page (halaman utama), halaman utama ini akan mempunyai halaman percabangan yang dikatakan Slave Page (halaman pendukung). Jika salah satu halaman pendukung dipilih atau diaktifkan, maka tampilan tersebut akan bernama Master Page (halaman utama kedua), dan seterusnya. Pada struktur ini tidak diperkenankan adanya tampilan secara Linear.

4. Campuran

Struktur penjejakan campuran (Composite) merupakan gabungan dari ketiga struktur sebelumnya yaitu Linear, Non Linear, Hierarchical. Struktur ini juga biasa disebut struktur bebas. Jika suatu tampilan membutuhkan percabangan, maka dapat dibuat percabangan, dan bila dalam percabangan tersebut terdapat suatu tampilan yang sama kedudukannya maka dapat dibuat struktur Linear dalam percabangan tersebut. Struktur ini banyak digunakan dalam pembuatan aplikasi karena struktur ini dapat memberikan interaktifitas yang lebih tinggi.

\subsubsection{ERD (Entity Relationship diagram)}

Menurut Simarmata (2010:67) adalah "alat pemodelan data utama dan akan membantu mengoranisasi data dalam suatu proyek ke dalam entitas-entitas dan menentukan hubungan antar entitas. Dalam Entity Relationship Diagram (ERD) terdapat beberapa komponen seperti:

1. Entity

Entity merupakan objek yang dapat dibedakan dengan yang lain dalam dunia nyata. Dalam entity ada yang disebut sebagai entity set yaitu kumpulan dari entity yang sejenis.

2. Atribut

Atribut adalah karakteristik dari entity atau relationship, yang menyediakan penjelasan detail tentang entity atau relationship tersebut. Atribut digambarkan dalam bentuk oval.

3. Relasi

Relasi adalah hubungan yang terjadi antara satu atau lebih entity.

4. Kardinalitas (Derajat Relasi)

Kardinalitas relasi menunjukkan jumlah maksimum entitas yang dapat berelasi dengan entitas pada himpunan entitas lain.

\subsubsection{LRS (Logical Record Structure)}

Menurut Ladjamudin (2006: 210) terdapat dua aturan dalam melakukan transformasi E-R Diagram ke Logical Record Structure (LRS). Dua aturan tersebut yaitu: 
1. Setiap entity akan diubah kebentuk sebuah kotak dengan nama entity berada diluar kotak dan atribut berada didalam kotak.

2. Sebuah relasi kadang disatukan dalam sebuah kotak bernama entity, kadang dipisah dalam sebuah kotak tersendiri.

Aturan pokok diatas akan sangat dipengaruhi oleh elemen yang menjadi titik perhatian utama pada langkah transformasi yaitu cardinality/kardinalitas.

\section{HASIL DAN PEMBAHASAN}

\subsection{Tinjauan Perusahaan}

Dengan ekspansi yang cepat, pada tahun 2002, Penjualan dan distribusi dilakukan oleh PT. Pangan Sehat Sejahtera, selain penjualan dan distribusi PT. Pangan Sehat Sejahtera juga bertanggung jawab untuk semua kegiatan pemasaran. Selama bertahun-tahun perjalanannya, termasuk menghadapi tahun yang sulit dari krisis ekonomi pada tahun 1998, perusahaan telah mencatat sejumlah ekspansi pasar strategis di seluruh nusantara. Mulai dari cakupan pemasaran yang sangat kecil di Jakarta pada tahun 1995, perusahaan memperluas pasarnya ke tanah Jawa dengan menunjuk CV. Langgeng Lestari pada tahun 1996. Ekspansi pasar mulai berguling ke Jawa Barat, Jawa Tengah, Pulau Sumatera, Kalimantan, dan Sulawesi, serta PT. Pangan Mitra Sejahtera untuk wilayah akses Jawa Timur dan Bali. Akhirnya pada tahun 2008, perusahaan telah membangun cold storage modern yang beralamatkan di Komp. Jababeka I Blok J No 7C Jln Jababeka VI Cikarang Industrial Estate-Bekasi.

\subsection{Analisa Kebutuhan}

\subsubsection{Kebutuhan Pengguna}

Dalam aplikasi ini terdapat tiga pengguna yang dapat saling berinteraksi dalam lingkungan sistem, yaitu: Bagian Pembelian, Bagian Penjualan, Dan Manajerial. Ketiga pengguna tersebut memiliki karakteristik interaksi dengan sistem yang berbeda-beda dan memiliki kebutuhan informasi yang berbeda-beda, seperti berikut:

1. Skenario Kebutuhan Bagian Pembeliaan
a) Mengelola data Supplier
b) Membuat permintaan barang
c) Mengelola data barang masuk
d) Mengecek laporan stok barang
e) Membuat laporan barang masuk
f) Membuat laporan supplier

2. Skenario Kebutuhan Penjualan
a) Mengelola data pelanggan
b) Mengelola data pengeluaran barang
c) Mengelola pengembalian barang (retur)
d) Mengecek laporan stok barang
e) Membuat laporan pengeluaran barang
f) Membuat laporan pelanggan

3. Skenario Kebutuhan Manajer

Hanya dapat melihat akses semua laporan modul

3.2.2 Kebutuhan Sistem

1. Pengguna harus melakukan login terlebih dahulu untuk dapat mengakses aplikasi ini dengan memasukan username dan password agar privasi masing-masing pengguna tetap terjaga keamananya.

2. Pengguna harus melakukan logout setelah selesai menggunakan aplikasi.

3. Bagian pembelian input master data supplier.

4. Bagian pembelian input data pembelian barang.

5. Bagian pembelian melakukan laporan data barang.

6. Bagian penjualan melakukan input data pelanggan.

7. Bagian penjualan melakukan input data pengeluaran dan retur barang.

8. Sales membuat laporan data pelanggan dan data pengeluaran.

9. Sistem melakukan kalkulasi stok barang. 
Jurnal Inkofar * Volume 1 No. 2, Desember 2017 * ISSN: 2615-3645 (Print) / 2581-2920 (Online) Tersedia secara online di: http://www.politeknikmeta.ac.id/meta/ojs/

3.3 Rancangan Perangkat Lunak

3.3.1 Rancangan Halaman Index

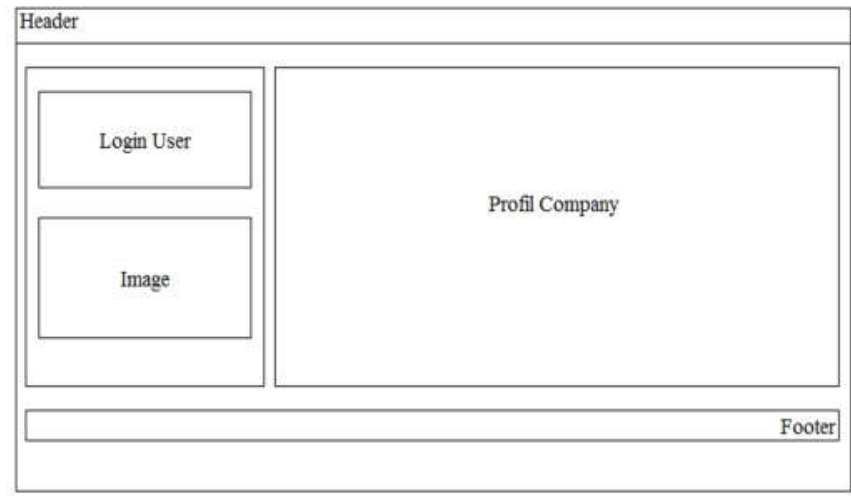

Gambar 1. Rancangan Halaman Index

3.3.2 Rancangan Halaman pembelian

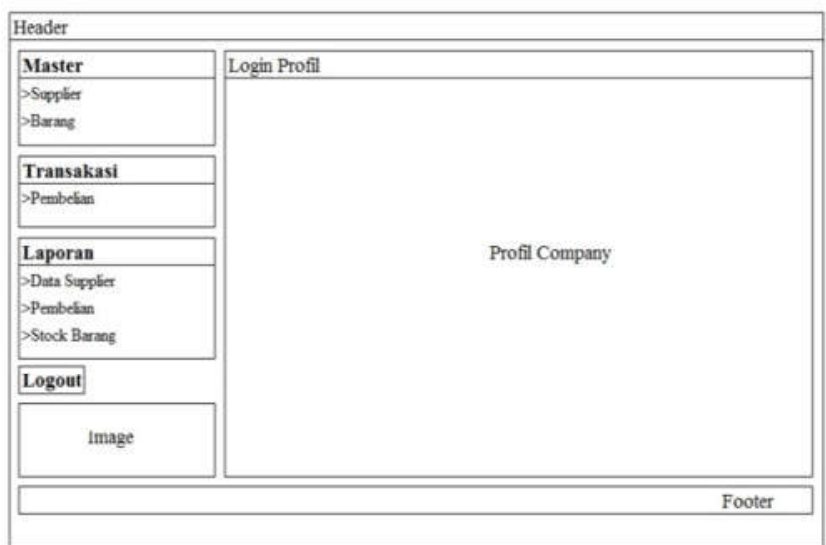

Gambar 2. Rancangan Halaman Pembelian

3.4 Rancangan Basis Data

3.4.1 ERD (Entity Relationship Diagram (ERD)

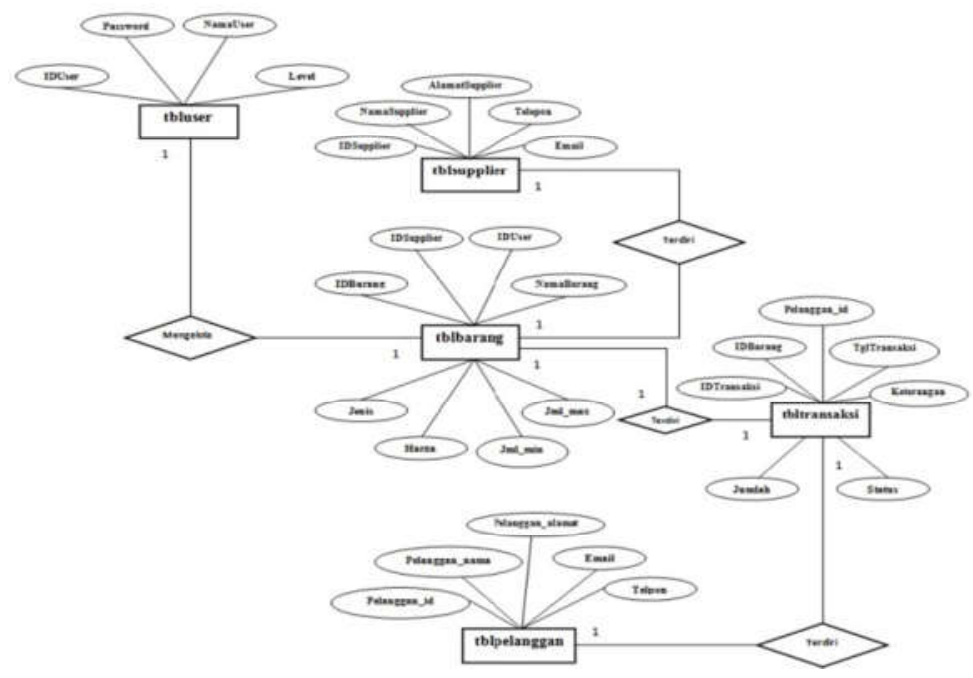

Gambar 3. Entity Relationship Diagram (ERD) 
3.4.2 Logical Relational Structure (LRS)

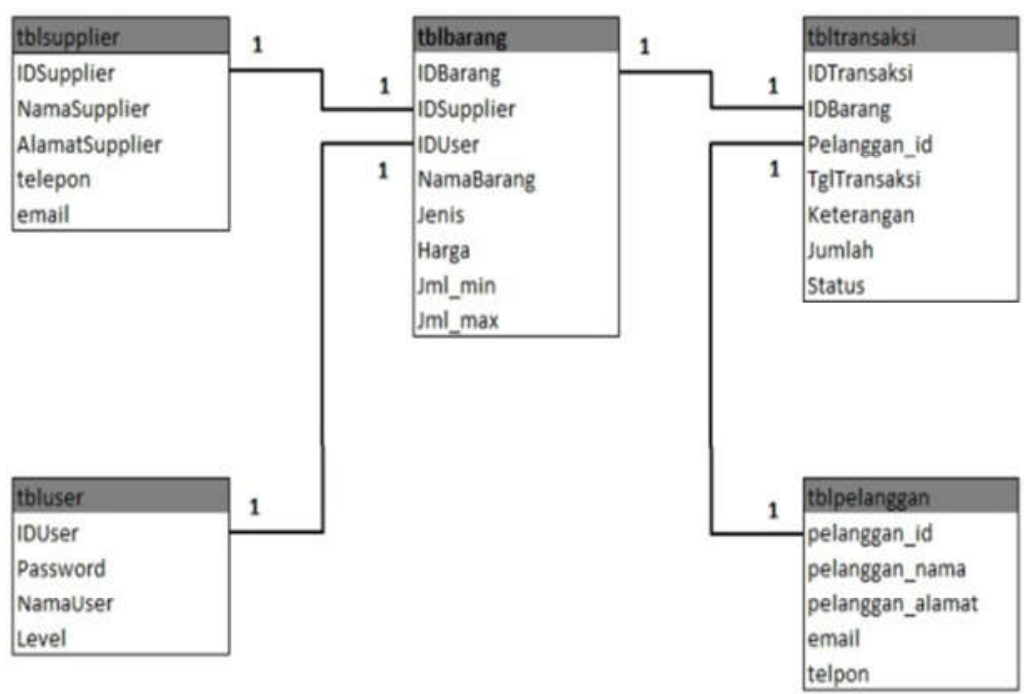

Gambar 4. Logical Relation Structure (LRS)

3.5 Rancangan Struktur Navigasi

3.5.1 Implementasi dan pengujian unit user

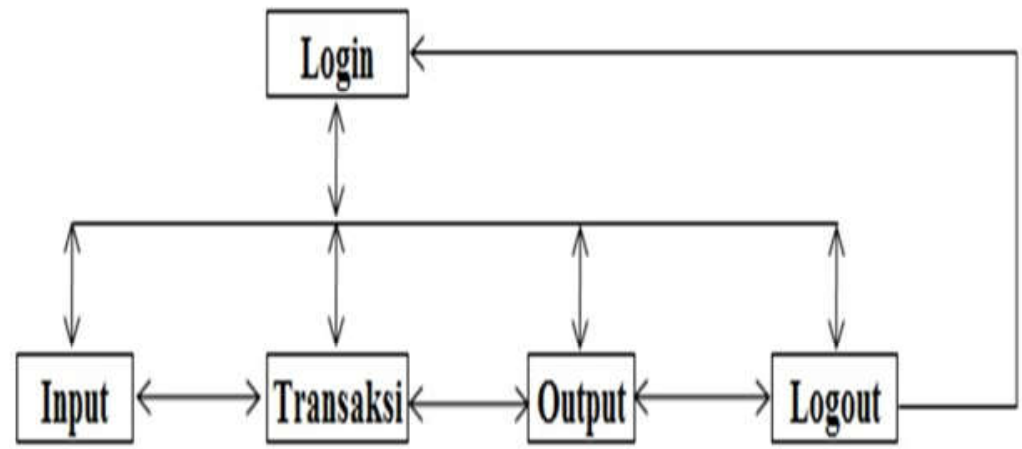

Gambar 5. Logical Relation Structure (LRS)

3.5.2 Implementasi dan pengujian unit pembelian

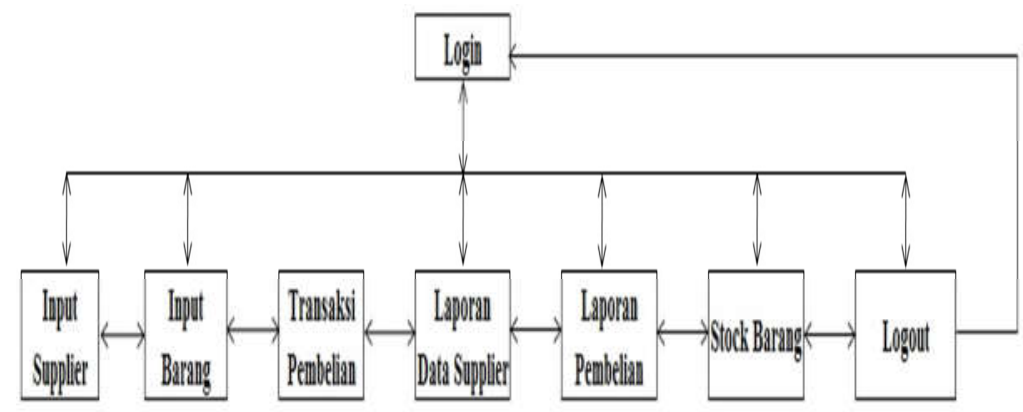

Gambar 6. Logical Relation Structure (LRS) 
Jurnal Inkofar * Volume 1 No. 2, Desember 2017 * ISSN: 2615-3645 (Print) / 2581-2920 (Online) Tersedia secara online di: http://www.politeknikmeta.ac.id/meta/ojs/

3.6 Implementasi dan Pengajuan Unit

3.6.1 Implementasi halaman Index

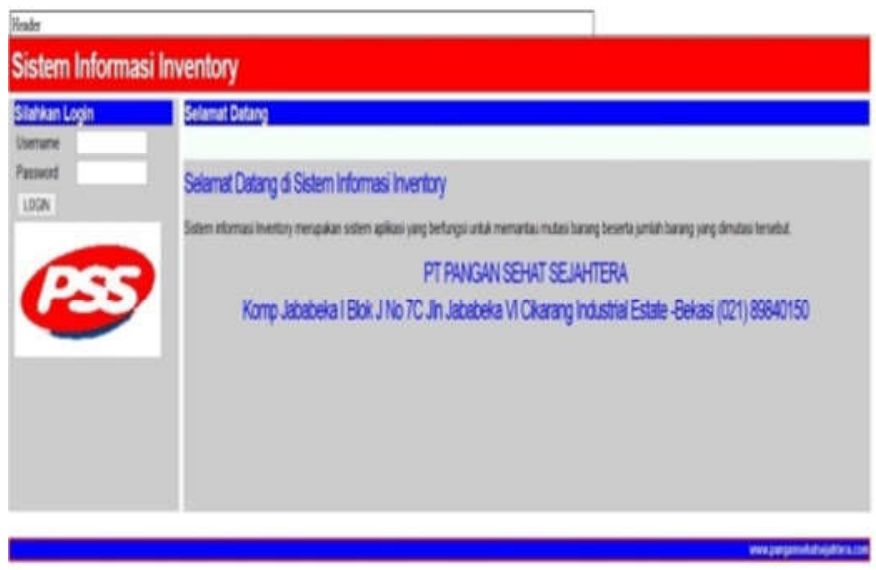

\section{Gambar 7. Implementasi Halaman Index}

3.6.2 Implementasi halaman Bagian Pembelian

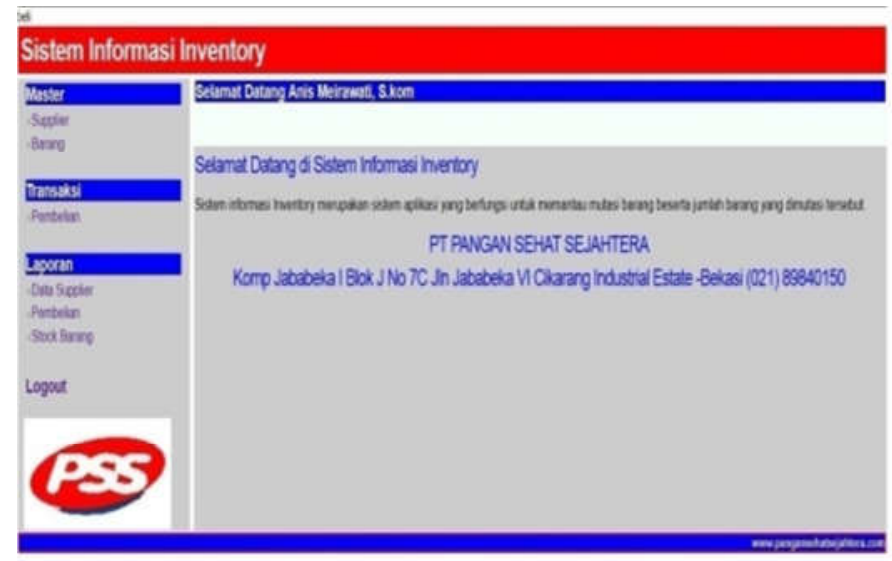

Gambar 8. Implementasi Halaman bagian pembelian

3.6.3 Implementasi halaman transaksi pembelian

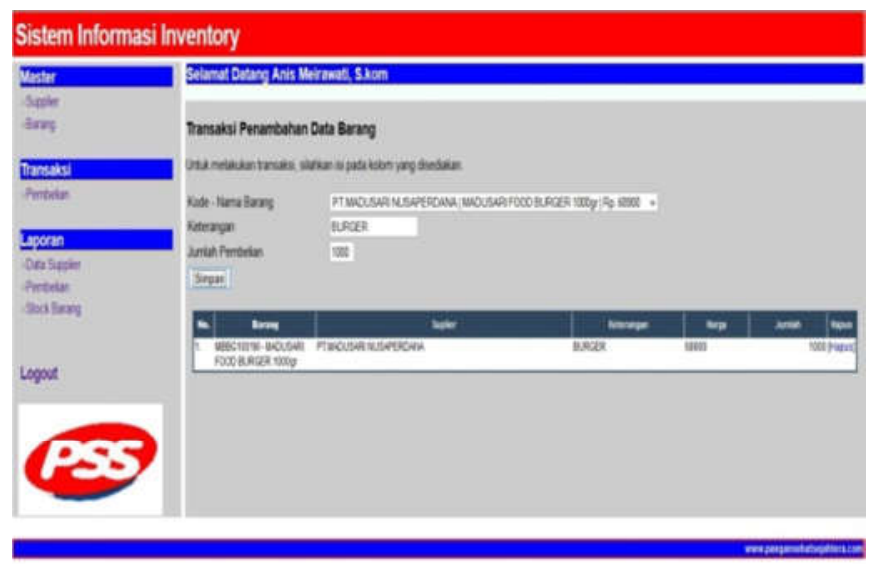

Gambar 9. Implementasi Halaman transaksi pembelian 


\subsection{Sfesifikasi Sistem Komputer}

Mengatur tentang penggunaan dari perangkat keras dan perangkat lunak yang akan digunakan dalam sistem usulan dan penggambarannya dalam bentuk konfigurasi komputer.

3.7.1 Spesifikasi Perangkat Keras

Perangakat keras merupakan sarana fisik yang di pergunakan untuk dapat menghasilkan data, program dan keluaran. Dan agar program dapat berjalan sesuai dengan karakteristik tersebut dengan perangkat keras yang dibutuhkan minimal:

1. Server
a) $\quad C P U$
Processor intel ${ }^{\circledR}$ Pentium Core 2 Duo.
RAM DDR3 $4 G B$.
Harddisk $500 \mathrm{~GB}$.
b) Mouse
c) Keyboard
d) Monitor dengan resolusi layar minimum 1024x768.
e) Koneksi internet dengan kecepatan $3 \mathrm{Mbps}$

2. Client
a) $\quad C P U$

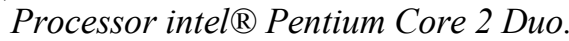
RAM DDR3 $1 \mathrm{~GB}$.
Harddisk $160 \mathrm{~GB}$.
b) Mouse
c) Keyboard
d) Monitor dengan resolusi layar minimum 1024x768.
e) Koneksi internet dengan kecepatan $3 \mathrm{Mbps}$

\subsubsection{Spesifikasi Perangkat Lunak}

Perangkat lunak atau disebut software adalah komponen non fisik yang terdiri dari kumpulan program yang di buat terstruktur datanya. Agar dapat berjalan diperlukan system operasi yang mendukung program aplikasi yang berfungsi untuk mengatur data dan dapat disimpan di dalam hardisk serta dapat tercetak. Agar program dapat berjalan sesuai dengan karakteristik tersebut, dibutuhkan perangkat lunak dengan syarat minimal:

1. Server

a) Sistem operasi

Sistem operasi yang umum digunakan seperti: Microsoft Windows atau linux (Ubuntu, Fedora, dll)

b) Aplikasi bundle web server seperti: Xampp, WampServer, php, Apache2Triad yang terdiri dari beberapa komponen

c) Aplikasi Web Lihatr Seperti Mozilla Firefox, Opera, Safari, Internet explorer, Google Chrome.

2. Client

a) Sistem operasi yang umum digunakan seperti: Microsoft Windows atau linux (Ubuntu, Fedora, dll)

b) Aplikasi Web Lihatr Seperti Mozilla Firefox, Opera, Safari, Internet explorer, Google Chrome.

\section{KESIMPULAN}

Dengan adanya sistem informasi perssedian barang pada PT. Pangan Sejahtera, Saya dapa menambil kesimpulan sebagai:

1. Implementasi dari Sistem Informasi Persediaan Barang ini dapat mendata aset secara akurat dan sesuai antara data pada pembukuan dengan kenyataan fisik barang yang ada.

2. Database aset dihasilkan dari penetapan dan migrasi data sebagai hasil dari pengembangan database Inventory.

3. Pembuatan laporan data aset yang akurat.

4. Pengolahan data yang terkomputerlisasi akan memeprcepat pengolahan data serta dapat menghemat waktu pemprosesan transaksi 


\section{DAFTAR PUSTAKA}

Sommerville, Ian, 2007, Software Engineering-Eight Edition, AddisonWesley, Massachussets.

Ardhana, YM Kusuma. 2012. PHP Menyelesaikan Website 30 Juta. Jakarta: Jasakom.

Binanto, Iwan. 2010. Multimedia Digital Dasar Teori + Pengembangannya. Yogyakarta : Andi Offset. Febrian, Jack. 2008. Menggunakan Internet. Bandung : Informatika.

Firdaus. 2007. $P H P \& M y S Q L$ dengan Dreamweaver. Palembang: Maxikom

Kadir, Abdul. 2009. Dasar Pemrograman Web Dinamis Menggunakan PHP (Revisi). Yogyakarta: ANDI.

Oetomo, Budhi. 2007. Pengantar Teknologi Informasi Internet. Yogyakarta : Andi Offset.

Purnama. 2006. Panduan Pengembangan Diri. Jakarta : Badan Standar Nasional Pendidikan dan Pusat Kurikulum.

Rosa, A. S. dan M Shalahuddin 2013. Rekayasa Perangkat Lunak Terstruktur dan Berorientasi Objek. Bandung: Informatika.

Simarmata, Janner., dan Imam Prayudi. 2010. Basis Data. Yogyakarta: CV. Andi Offset.

Suprianto, Dodit. 2008. Buku Pintar Pemograman PHP. Jakarta : Oase Media.

Wismakarma, Komang. 2009. Membuat Catalog Online Dengan PHP dan CSS. Yogyakarta : Lokomedia.

Ladjamudin, Al Bahra. 2006, Rekayasa Perangkat Lunak, Penerbit Graha Ilmu, Yogyakarta. 